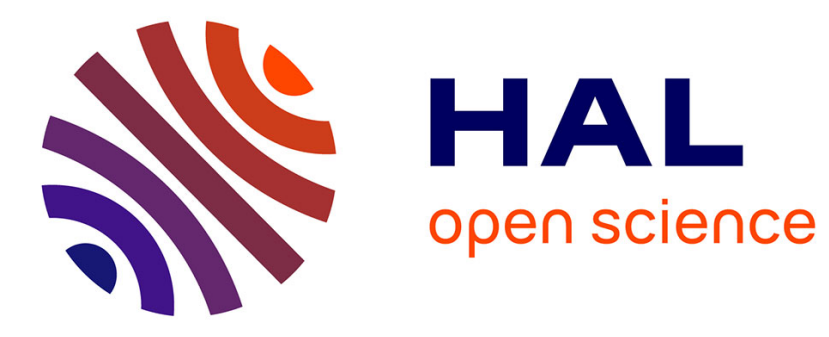

\title{
Rapid formation of mature microbialites in Lake Alchichica, Mexico
}

Miguel Iniesto, David Moreira, Karim Benzerara, Elodie Muller, Paola Bertolino, Rosaluz Tavera, Purificación López-garcía, Purificación López-García

\section{To cite this version:}

Miguel Iniesto, David Moreira, Karim Benzerara, Elodie Muller, Paola Bertolino, et al.. Rapid formation of mature microbialites in Lake Alchichica, Mexico. Environmental Microbiology Reports, 2021, 13 (5), pp.600-605. 10.1111/1758-2229.12957 . hal-03384295

\section{HAL Id: hal-03384295 https://hal.science/hal-03384295}

Submitted on 18 Oct 2021

HAL is a multi-disciplinary open access archive for the deposit and dissemination of scientific research documents, whether they are published or not. The documents may come from teaching and research institutions in France or abroad, or from public or private research centers.
L'archive ouverte pluridisciplinaire HAL, est destinée au dépôt et à la diffusion de documents scientifiques de niveau recherche, publiés ou non, émanant des établissements d'enseignement et de recherche français ou étrangers, des laboratoires publics ou privés. 


\section{Rapid formation of mature microbialites in Lake Alchichica, Mexico}

2

3 Miguel Iniesto ${ }^{1}$, David Moreira ${ }^{1}$, Karim Benzerara ${ }^{2}$, Elodie Muller ${ }^{2}$, Paola Bertolino $^{1}$, Rosaluz Tavera ${ }^{3}$ and

4 Purificación López-García ${ }^{1}$

5

$6{ }^{1}$ Unité d'Ecologie Systématique et Evolution, CNRS, Université Paris-Saclay, AgroParisTech, Orsay,

7 France

$8{ }^{2}$ Institut de Minéralogie, de Physique des Matériaux et de Cosmochimie, CNRS, Muséum National

9 d'Histoire Naturelle, Sorbonne Université, Paris, France

$10{ }^{3}$ Departamento de Ecología y Recursos Naturales, Universidad Nacional Autónoma de México, DF

11 Mexico, Mexico

12

13 For correspondence: puri.lopez@u-psud.fr

14

15

16

17

18 Running title: Rapid microbialite formation in Lake Alchichica 


\section{Originality-Significance Statement}

20 Microbialites are rocks formed by the activity of complex microbial communities that sequester $\mathrm{CO}_{2}$ in 21 the form of biomass and mineral carbonates. However, little is known about microbialite growth rate 22 and the steps that take place early during their formation. Here, we show that nascent, mm-sized 23 microbialites form on Nylon mesh after two years of exposure in the alkaline Lake Alchichica, which 24 harbors extensive hydromagnesite and aragonite microbialites. The associated prokaryotic and 25 eukaryotic microbial communities were not significantly different of those associated to mature 26 microbialite of the lake. However, only thin microbial biofilms developed on aragonite and hydromagnesite crystals, despite the fact that their microbial communities were similar to those associated to mature microbialites. Our results show that mature microbialites can form very rapidly (up to $1 \mathrm{~mm} /$ year) on some surfaces but not on others and open intriguing questions about carbonate nucleation that deserve future exploration. 
31 Microbialites are emblematic sedimentary rocks formed by phylogenetically and metabolically complex 32 microbial communities thriving under specific physicochemical conditions. Most microbialites are 33 photosynthesis-based ecosystems frequently formed by carbonates, thereby capturing inorganic carbon 34 in the form of both, organic matter and mineral precipitates. However, little is known about the amount of sequestered carbon and the kinetics of the process, i.e. microbialite growth rate. To assess microbialite growth rate and the influence of substrates on carbonate formation in Alchichica, an alkaline crater lake harboring well-developed carbonate microbialites, we incubated in situ sterilized Nylon mesh, hydromagnesite and aragonite crystals, and bleached-coral aragonite for two years. We observed the rapid formation of nascent hydromagnesite and aragonite-containing microbialites on Nylon mesh, with an average growth rate of 0.6 (and up to 1 ) $\mathrm{mm} /$ year. By contrast, only thin ( $<0.2 \mathrm{~mm}$ ) biofilms developed on exposed hydromagnesite and aragonite crystals and bleached-coral aragonite, suggesting decoupled microbial colonization and biomineralization and/or potential interference of those mineral surfaces with new carbonate nucleation. Microbial communities associated with 2-year-old microbialites and biofilms were fully comparable to mature communities populating Lake Alchichica indigenous microbialites. 
52 Microbialites are organosedimentary structures formed under the influence of phylogenetically and

53 functionally diverse microbial communities in particular physicochemical environments (Riding, 2000; 54 Dupraz and Visscher, 2005). Microbialites are not only emblematic as the oldest undisputed traces of life on Earth ( 3.5 Ga-old laminated microbialites or stromatolites)(Tice and Lowe, 2004; Allwood et al., 2006) but also constitute poorly understood carbon traps (Ahrendt et al., 2014; McCutcheon et al., 2014; McCutcheon et al., 2019). Most marine and freshwater microbialites are formed by photosynthesis-based microbial communities that favor carbonate precipitation by locally increasing the alkalinity (Dupraz and Visscher, 2005; Dupraz et al., 2009) and/or upon an alkalinity threshold (Zeyen et al., 2017; Iniesto et al., 2020). Consequently, they constitute carbon reservoirs in the form of both, biomass and solid carbonates. To ascertain if microbialite systems are efficient carbon sinks, more quantitative measurements are needed. However, relatively little is known about early microbialite formation and growth rate. Short-term ${ }^{13} \mathrm{C} /{ }^{14} \mathrm{C}$-labeling experiments suggest that carbonate precipitation occurs, albeit with low rates $(0.05 \mathrm{~mm} / \mathrm{year}$ ) in Lake Pavilion (Brady et al., 2009), but other systems seem to have much higher rates, in the 0.2-0.6 mm/year range (Chivas et al., 1990; Carvalho et al., 2017).

Recent comparative studies in lakes from the Trans-Mexican volcanic belt showed that microbialite size and community structure significantly correlate with alkalinity (Zeyen et al., 2017; Iniesto et al., 2020), suggesting that local biotic and abiotic factors result in different growth rates. In particular, Lake Alchichica, an alkaline $\left(\mathrm{pH}^{\sim}\right.$; $\left.\left[\mathrm{HCO}_{3}^{-}\right] \sim 40 \mathrm{mM}\right)$ and relatively Mg-rich $\left(\left[\mathrm{Mg}^{2+}\right] \sim 17 \mathrm{mM}\right)$ crater lake located at high altitude (2,300 m above sea level) displays massive (meter-sized) microbialites, mostly non-laminated (thrombolites), composed of hydromagnesite $\left(\mathrm{Mg}_{5}\left(\mathrm{CO}_{3}\right)_{4}(\mathrm{OH})_{2} \cdot 4\left(\mathrm{H}_{2} \mathrm{O}\right)\right)$ and aragonite $\left(\mathrm{CaCO}_{3}\right)$ that precipitate in situ (Kazmierczak et al., 2011; Couradeau et al., 2013; Gerard et al., 2013). Microbial communities associated to these structures have been previously studied using 16S/18S rRNA gene metabarcoding and metagenomic approaches (Couradeau et al., 2011; Saghaï et al., 2016; Valdespino-Castillo et al., 2018). Interestingly, core microbial communities shared by microbialites across various lakes accounted for higher proportions of the total microbial community in the highestalkalinity sites, notably Alchichica (Iniesto et al., 2020). Various indicators, such as active carbonate precipitation observed in the water column and the presence of more or less developed microbialites on plants growing on the rim of the lake as well as plastic bottles and tires abandoned on the lake shore, suggested that microbialite formation is an active and relatively fast process in Lake Alchichica. However, details about the first steps, including growth rate, of microbialite formation in this lake were missing. 
86 To evaluate the capacity of calcifying microbial communities to colonize different surfaces and form new 87 microbialites as well as to assess microbialite growth rate, we placed sterilized crystals of 88 hydromagnesite and aragonite as well as bleached-coral fine-grained aragonite in extensively 89 perforated 50-ml Falcon tubes that were capped with $200 \mu \mathrm{m}$-pore diameter Nylon mesh pieces 90 (Fig.1A). These colonization devices were immersed at $0.5 \mathrm{~m}$ depth in the North shore of Lake Alchichica 91 from January 2012 to May 2014. Nascent microbialites and biofilms growing on the incubated substrates were then collected, as well as, for comparison, fragments from large older microbialites growing at equivalent depth $(0-3 \mathrm{~m})$ below the water surface on the North and West shores (Supplementary Methods, Supplementary Fig.1 and Supplementary Table 1) at sampling points previously studied (Couradeau et al., 2011; Saghaï et al., 2015; Saghaï et al., 2016; Iniesto et al., 2020).

After the 28 month-incubation period, small, distinct microbialite structures of up to approximately $2 \mathrm{~mm}$ in diameter could be observed growing on the Nylon mesh that was used as permeable barrier capping the Falcon tubes (Fig.1A-C). These formed discrete structures that tended to merge, and not a continuous calcifying biofilm, highlighting the importance of local nucleation. Individual measurements allowed an estimation of an average microbialite growth of $\sim 0.6 \mathrm{~mm} / \mathrm{year}$ (and up to $1 \mathrm{~mm} / \mathrm{year}$ ), although this growth rate might be different for already growing structures. No macroscopically visible stratification or lamination was observed. To determine the overall mineral composition of these incipient structures, we applied attenuated total reflection Fourier transform infrared (ATR-FTIR) spectroscopy (Supplementary Methods). The obtained spectra highlighted their composite nature, unambiguously showing the occurrence of two distinct carbonate phases: hydromagnesite and aragonite (Fig.1D). In addition, we detected a silica-rich phase, possibly associated with diatom frustules (ochrophytes; Fig.2C and D). This mineral composition is consistent with previous observations made on mature microbialites from this lake site (Zeyen et al., 2019), indicating that nascent microbialites have a similar overall mineral composition to well-established microbialites. Furthermore, since hydromagnesite is the carbonate mineral spontaneously precipitating in the lake (Couradeau et al.,

111 2011; Kazmierczak et al., 2011) and aragonite has been shown to be spatially associated with particular 112 microbial groups, notably some cyanobacteria (Gerard et al., 2013; Saghaï et al., 2015), the observed 113 composition strongly suggests active biomineralization in nascent microbialites. By contrast, only a thin 114 biofilm (a few tens up to 1-200 $\mu \mathrm{m}$ ) but no apparent microbialitic structures formed on any of the 115 incubated mineral fragment surfaces, whatever their orientation, suggesting that microbial colonization 116 of surfaces can be uncoupled from biomineralization. The absence of microbialite formation on the 117 exposed mineral surfaces is unlikely to be strongly influenced by slight differences of physicochemical 118 conditions within the perforated Falcon tube compared to the surface of the Nylon mesh. First, mineral 119 fragments occupied around $5 \%$ of the inner 50-ml Falcon volume and water could circulate via the many 
3-5 mm diameter holes suggesting that, if there were chemical differences between the inside and

121 outside of the tube, these were minor. In any case, these differences would be comparable to those

122 found between small protected pockets in the very irregular cauliflower-like native microbialites, with

123 limited water circulation, and the open lake waters. Second, small pocket zones and irregular shapes in 124 native growing microbialites result in the existence of areas protected from direct light incidence. This, 125 together with the fact that microbialites actively develop from the surface of the lake to at least $40 \mathrm{~m}$ depth (personal observations), implies that the observed patterns cannot be easily explained by differences in light intensity and quality. Therefore, although these initial observations of biofilm-only formation on aragonite and hydromagnesite crystals after two years of exposure need to be confirmed by more extended experiments, the observed patterns might suggest some type of nucleation interference or inhibition caused by those mineral surfaces.

To determine the microbial community structure associated with these samples, we studied the prokaryotic and eukaryotic components of two nascent microbialites growing on the Nylon mesh and

133 the 2-year-old biofilms growing on the mineral substrates by a metabarcoding approach. We amplified

$13416 \mathrm{~S}$ and 18S rRNA gene fragments and massively sequenced the resulting amplicons using paired-end 135 Illumina MiSeq. After quality trimming, we built operational taxonomic units using SWARM and Cd-hit 136 at 97 and 98\% identity thresholds, which yielded comparable prokaryotic OTU numbers (Supplementary 137 Methods; Supplementary Table 2). We retained SWARM clustering for subsequent analyses due to the 138 resulting lower, more tractable, number of eukaryotic OTUs. OTUs were assigned to phyla and/or high139 rank taxa by sequence similarity and, for divergent OTUs, phylogenetic placement in reference 140 phylogenetic trees (Supplementary Tables 3-4). The community structure of nascent microbialites but 141 also of the biofilms was comparable to that of mature Alchichica microbialites in terms of relative 142 abundance and, most especially, OTU diversity (Fig.2A-D). This was further shown by the scattering of 143 mature and young samples in a non-metric multidimensional scaling (NMDS) ordination analysis (Fig.2E; 144 Supplementary Fig.5). Prokaryotic communities were rich in Cyanobacteria and their associated 145 hydrocarbon-scavenging taxa (Bacteroidetes, Planctomycetes, Verrucomicrobia). Anoxygenic 146 photosynthetic bacteria were also abundant, notably Chloroflexi and some Alphaproteobacteria 147 (Rhodobacterales, Rhodospirillales), but also some Gammaproteobacteria (Chromatiaceae) and minor 148 proportions of Chlorobi. Green algae and diatoms (ochrophytes), together with ciliate and fungi were 149 the most relatively abundant eukaryotes. However, because they represent a minor part compared to 150 the prokaryotic component (Saghaï et al., 2016), the relative abundance of eukaryotic taxa is likely 151 affected by higher stochasticity. Only minor differences appeared in terms of relative abundance of 152 major groups; the most notable being the presence of a higher proportion of the Thermus-Deinococcus 153 clade in the sampled aragonite-colonizing biofilm (Fig.2A). Despite these minor differences, the two 154 nascent microbialites and the three mineral-associated biofilms shared over 900 OTUs with mature 
156 These shared OTUs represented $80-90 \%$ of the total prokaryotic OTUs, and $87-97 \%$ of the total

157 eukaryotic OTUs, in Alchichica N and W samples, nascent microbialites and mineral-associated biofilms 158 (Fig.2G-H; Supplementary Table 5). PERMANOVA pairwise comparisons showed that differences 159 between mature, nascent microbialite communities or 2-year-old biofilms growing on incubated 160 minerals were not significant or very marginally so ( $p$-value 0.05 - 0.83; Supplementary Table 6). Biofilm 161 and microbialite communities were very different from planktonic communities along the water column of the lake (Iniesto et al., submitted). This can be easily visualized in an NMDS plot, where microbialiteassociated and planktonic communities clearly clustered apart (Supplementary Fig. 6).

Collectively, our results show a rapid colonization dynamics of certain newly available inert surfaces (Nylon mesh, but also plastic bottles or plants on site) in Lake Alchichica, with the formation of maturelike microbialites in terms of mineral and microbial community compositions in only two years. By contrast, although biofilms growing on incubated hydromagnesite and aragonite crystals, including coral aragonite, have similar microbial composition to that of mature microbialites, carbonate precipitation does not occur at visible scale. This suggests an uncoupling between community assembly and induced biomineralization on these surfaces and/or a potential interference of hydromagnesite and aragonite crystalline surfaces with microbialite carbonate nucleation, opening intriguing questions about carbonate nucleation in these natural ecosystems.

\section{Acknowledgments}

175 We thank A. Lopez-Archilla, A. Saghaï, N. Zeyen and E. Cortes for help and discussions during the 2014 176 field trip, and G. Reboul and P. Deschamps for bioinformatic advice. This research was funded by the 177 European Research Council Grants ProtistWorld (322669, PL-G) and PlastEvol (787904, DM) and the 178 French ANR project Microbialites (ANR-18-CE02-0013-01; PL-G/KB).

\section{References}

Ahrendt, S.R., Mobberley, J.M., Visscher, P.T., Koss, L.L., and Foster, J.S. (2014) Effects of Elevated Carbon Dioxide and Salinity on the Microbial Diversity in Lithifying Microbial Mats. Minerals 4: 145169.

Allwood, A.C., Walter, M.R., Kamber, B.S., Marshall, C.P., and Burch, I.W. (2006) Stromatolite reef from the Early Archaean era of Australia. Nature 441: 714-718.

Brady, A.L., Slater, G., Laval, B., and Lim, D.S. (2009) Constraining carbon sources and growth rates of freshwater microbialites in Pavilion Lake using (14)C analysis. Geobiology 7: 544-555. Environmental Changes. Radiocarbon 60: 383-393. 
Chivas, A.R., Torgersen, T., and Polach, H.A. (1990) Growth rates and Holocene development of stromatolites from Shark Bay, Western Australia. Australian Journal of Earth Sciences 37: 113-121.

Couradeau, E., Benzerara, K., Moreira, D., Gerard, E., Kazmierczak, J., Tavera, R., and Lopez-Garcia, P. (2011) Prokaryotic and eukaryotic community structure in field and cultured microbialites from the alkaline Lake Alchichica (Mexico). PLoS One 6: e28767.

Couradeau, E., Benzerara, K., Gérard, E., Estève, I., Moreira, D., Tavera, R., and López-García, P. (2013) In situ microscale cyanobacterial calcification in modern microbialites. Biogeosciences 10: 52555266.

Dupraz, C., and Visscher, P.T. (2005) Microbial lithification in marine stromatolites and hypersaline mats. Trends Microbio/ 13: 429-438.

Dupraz, C., Reid, R.P., Braissant, O., Decho, A.W., Norman, R.S., and Visscher, P.T. (2009) Processes of carbonate precipitation in modern microbial mats. Earth-Science Reviews 96: 141-162.

Gerard, E., Menez, B., Couradeau, E., Moreira, D., Benzerara, K., Tavera, R., and Lopez-Garcia, P. (2013) Specific carbonate-microbe interactions in the modern microbialites of Lake Alchichica (Mexico). ISME J 7: 1997-2009.

Iniesto, M., Moreira, D., Reboul, G., Deschamps, P., Benzerara, K., Bertolino, P. et al. (2020) Core microbial communities of lacustrine microbialites sampled along an alkalinity gradient. Environ Microbiol 23: 51-68.

Kazmierczak, J., Kempe, S., Kremer, B., López-García, P., Moreira, D., and Tavera, R. (2011) Hydrochemistry and microbialites of the alkaline crater lake Alchichica, Mexico. Facies 57: 543-570.

McCutcheon, J., Power, I.M., Harrison, A.L., Dipple, G.M., and Southam, G. (2014) A greenhouse-scale photosynthetic microbial bioreactor for carbon sequestration in magnesium carbonate minerals. Environ Sci Technol 48: 9142-9151.

McCutcheon, J., Power, I.M., Shuster, J., Harrison, A.L., Dipple, G.M., and Southam, G. (2019) Carbon Sequestration in Biogenic Magnesite and Other Magnesium Carbonate Minerals. Environ Sci Technol 53: 3225-3237.

Riding, R. (2000) Microbial carbonates: the geological record of calcified bacterial-algal mats and biofilms. Sedimentology 47: 179-214.

Saghaï, A., Zivanovic, Y., Moreira, D., Benzerara, K., Bertolino, P., Ragon, M. et al. (2016) Comparative metagenomics unveils functions and genome features of microbialite-associated communities along a depth gradient. Environ Microbiol 18: 4990-5004.

Saghaï, A., Zivanovic, Y., Zeyen, N., Moreira, D., Benzerara, K., Deschamps, P. et al. (2015) Metagenomebased diversity analyses suggest a significant contribution of non-cyanobacterial lineages to carbonate precipitation in modern microbialites. Front Microbio/ 6: 797.

Tice, M.M., and Lowe, D.R. (2004) Photosynthetic microbial mats in the 3,416-Myr-old ocean. Nature 431: 549-552.

Valdespino-Castillo, P.M., Hu, P., Merino-Ibarra, M., Lopez-Gomez, L.M., Cerqueda-Garcia, D., GonzalezDe Zayas, R. et al. (2018) Exploring biogeochemistry and microbial diversity of extant microbialites in Mexico and Cuba. Front Microbiol 9: 510.

Zeyen, N., Daval, D., Lopez-Garcia, P., Moreira, D., Gaillardet, J., and Benzerara, K. (2017) Geochemical conditions allowing the formation of modern lacustrine microbialites. Procedia Earth and Planetary Science 17: 380-383.

Zeyen, N., Benzerara, K., Menguy, N., Brest, J., Templeton, A.S., Webb, S.M. et al. (2019) Fe-bearing phases in modern lacustrine microbialites from Mexico. Geochim Cosmochim Acta 253: 201-230. 
240 Fig.1. Rapid growth of nascent microbialites in Lake Alchichica. A, photograph of colonization devices 241 deposited in the North shore of Lake Alchichica in January 2012 and collected in May 2014. B-C, detail

242 of the incipient microbialites growing on Nitex $200 \mu \mathrm{m}$-mesh sized membranes in the corresponding

243 areas framed in (A). D, ATR-FTIR spectrum showing the presence of hydromagnesite and aragonite 244 peaks.

246 Fig.2. Prokaryotic and eukaryotic community composition in mature and nascent microbialite samples 247 as well as biofilms growing on 2-year exposed mineral substrates in Lake Alchichica, Mexico. A, 248 histograms showing the phylogenetic diversity and relative proportion of 16S rRNA gene amplicon 249 sequences. B, phylogenetic diversity and relative abundance of prokaryotic operational taxonomic units 250 (OTUs) across phyla. C, phylogenetic diversity and relative proportion of $18 \mathrm{~S}$ rRNA gene amplicon 251 sequences. D, phylogenetic diversity and relative abundance of eukaryotic OTUs across phyla. Detailed 252 histograms of the categories Cyanobacteria, Alphaproteobacteria and 'Other Bacteria' are provided in 253 Supplementary Fig.2, those of Archaea and 'Other eukaryotes' are provided in, respectively, 254 Supplementary Figs.3A and 4. E, Non-metric multidimensional scaling (NMDS) biplot of the different 255 microbial communities associated to nascent microbialites and large mature microbialites growing on 256 the North and West shores of Lake Alchichica, as well as 2-year old biofilms growing on coral aragonite 257 (CA), aragonite (A) and hydromagnesite (HM). F, Venn diagram showing the number of OTUs shared by 258 the different groups of microbialite and mineral-associated 2-year old biofilm samples. G-H, relative 259 abundance and phylogenetic distribution of prokaryotic $(G)$ and eukaryotic $(H)$ core shared OTUs (as 260 shown in F). Detailed sample descriptions are provided in Supplementary Table 1; nasc. mic., nascent 261 microbialites. 

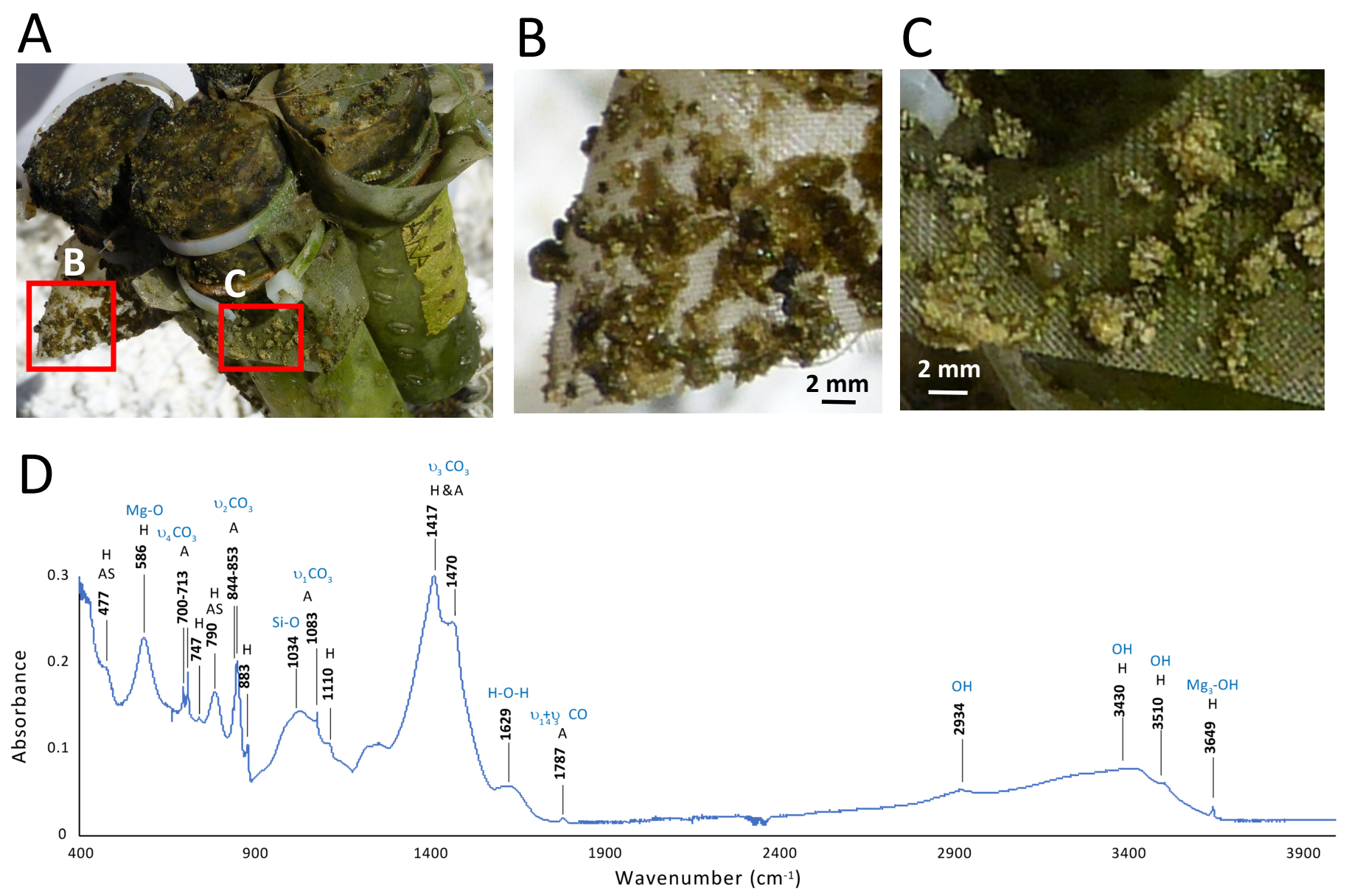

Figure 1. Iniesto et al. 
A

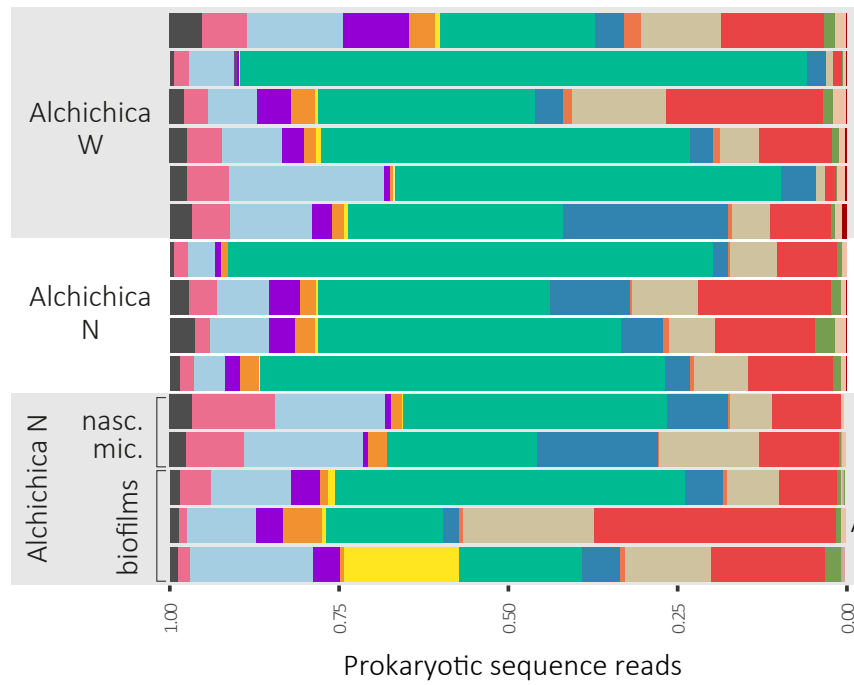

C

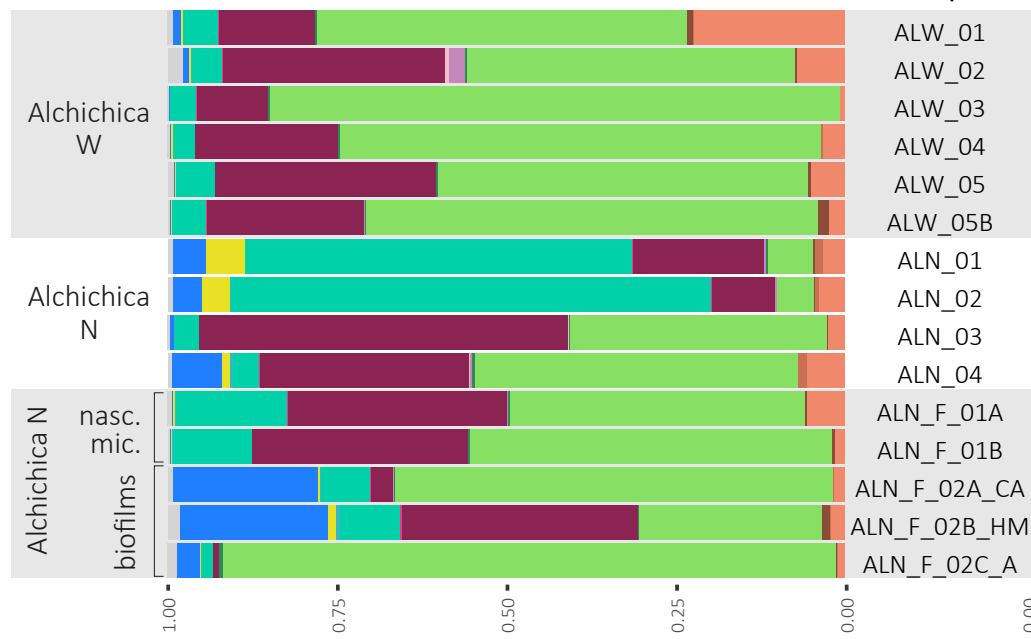

Eukaryotic sequence reads

E

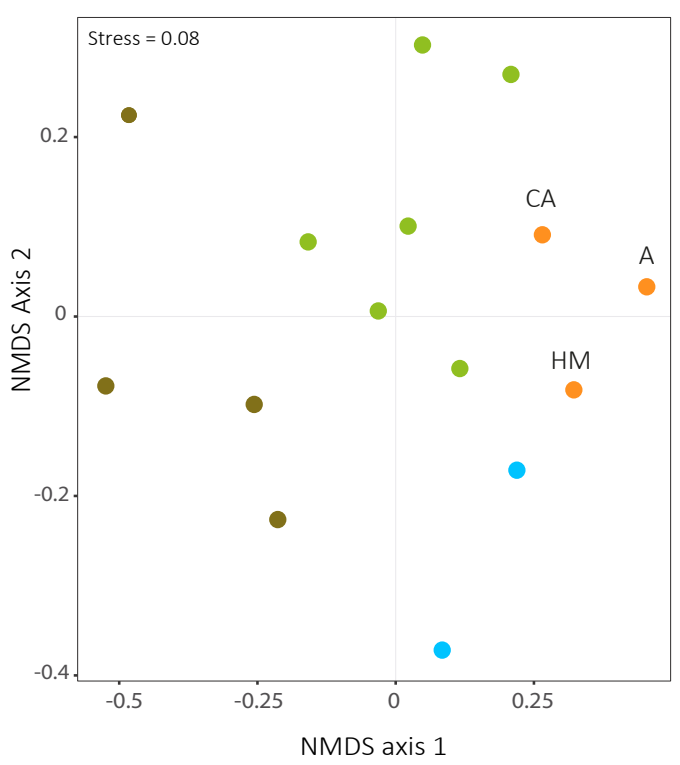

ALN_F_O2C_A
Sample

ALW_01

ALW_02

ALW_03

ALW_04

ALW_05

ALW_05B

ALN_01

ALN_02

ALN_03

ALN_04

ALN_F_01A

ALN_F_01B

ALN_F_02A_CA

ALN_F_02B_HM

:

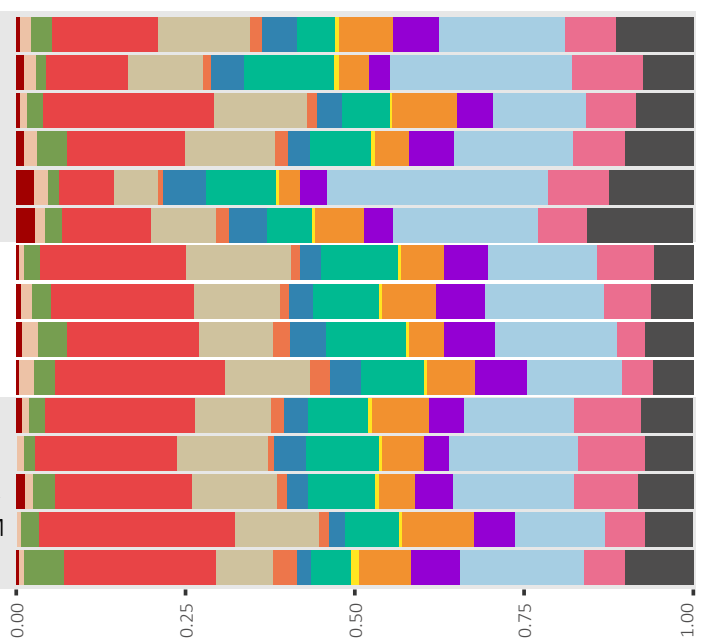

Archaea

Acidobacteria

Actinobacteria

Alphaproteobacteria

Bacteroidetes

Betaproteobacteria

Chloroflexiexi

Cyanobacteria

Deinococcus/Thermus

Deltaproteobacteria

Gammaproteobacteria

Planctomycetes

Verrucomicrobia

Other bacteria

Prokaryotic OTUs

D Alveolata

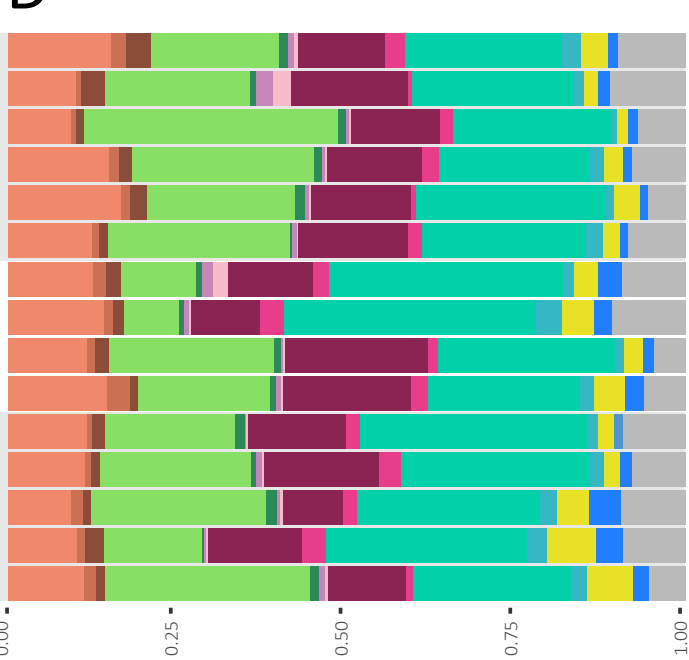

Ciliophora

Dinophyta

Other

Archaeplastida

Chlorophyta

Streptophyta

Other

Excavata

Euglenozoa

Other

Opisthokonta

Fungi

Other

Stramenopiles

Ochrophyta

Other

Other taxa

Eukaryotic OTUs

Cercozoa

Haptophyta

Other
F

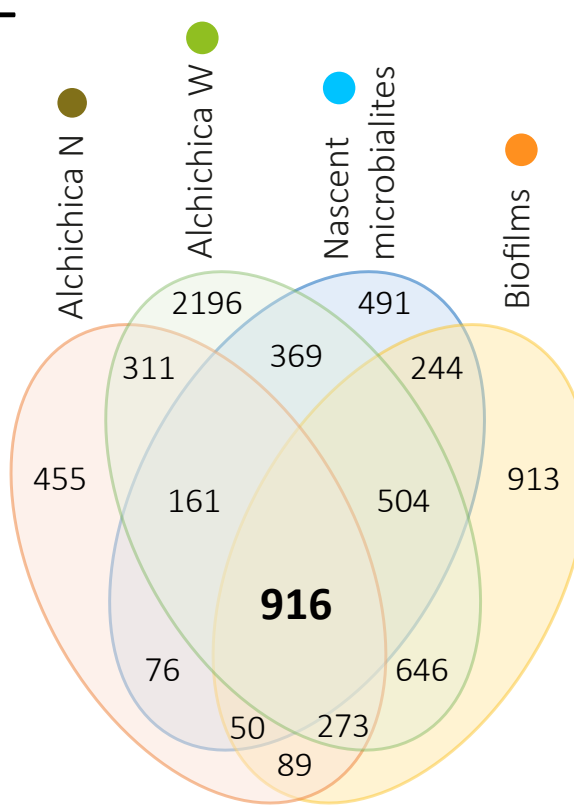

G

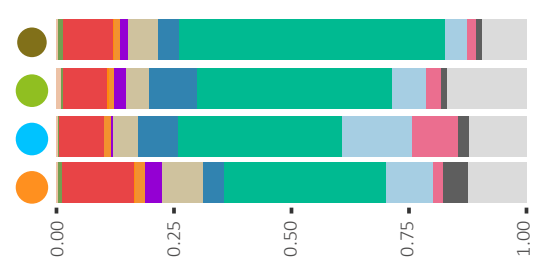

Relative abundance (prokaryotic OTUs)

$\mathrm{H}$

Not shared OTUs

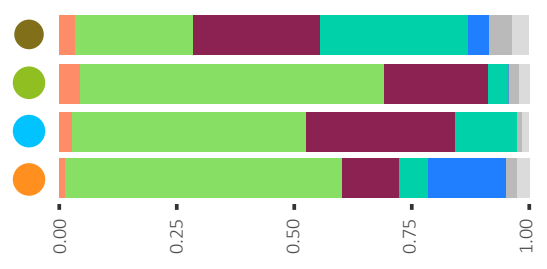

Relative abundance (eukaryotic OTUs)

Figure 2. Iniesto et al. 